\section{Pre-Membership Psychiatric Trainee}

The College has established a new grade known as 'Pre-Membership Psychiatric Trainee' for those in psychiatric training who have not yet passed the MRCPsych examination; this will replace the Inceptor grade following the Annual General Meeting on 11 July 2006.

The application process will be much simpler and quicker than has been the case for inceptors. The package will be attractive and useful and will include the trainee logbook, the Basic Specialist
Training Handbook, the examinations curriculum, titles from the Good Psychiatric Practice series and reading lists. Pre-Membership psychiatric trainees will receive discounted rates for conferences, the British Journal of Psychiatry and the Psychiatric Bulletin. They will also be entitled to subscribe to Advances in Psychiatric Treatment at the members' rate. There will be a dedicated annual meeting for new senior house officers in psychiatry for this grade only.

We hope to contact all new trainees in psychiatry as soon as they commence specialist training. Flyers and application forms will be sent to College tutors, with the request that they ensure that all new trainees receive a copy of each

Trainees will be invited to apply either online or by post, indicating the name of the training scheme. There will be no need for the tutor or consultant to countersign the application.

Once received, provided the trainee is registered with the General Medical Council (or the Medical Council in Ireland in the case of trainees in Ireland) and on an approved training programme, the application will be approved and a pack sent out.

\title{
obituaries
}

\section{Peter John Dally}

\section{Formerly Consultant \\ Psychiatrist at the \\ Westminster Hospital, London}

Peter Dally died on 25 June 2005, aged 82, in St Richard's Hospital, Chichester. For many years he was a senior consultant psychiatrist at the Westminster Hospital, where he worked as a general psychiatrist but developed one of the earliest specialist services for the treatment of anorexia nervosa. In 1996, 2 years after his retirement, The Riverside Mental Health Trust established the Peter Dally Clinic for Eating Disorders in recognition of his research and treatment initiatives in anorexia nervosa.

Peter's formative years of training in psychiatry were spent with William (Will) Sargant, arguably the best known, if controversial, psychiatrist of the time. Their first joint article on the treatment of anorexia nervosa was published in the British Medical Journal in 1960. The treatment relied heavily on the administration of drugs (chlorpromazine and modified insulin) and exerted great influence on clinicians. Previously patients with anorexia nervosa had been treated mainly by general physicians and the article was a signal to psychiatrists to venture into this area of therapeutics.

The 1960 paper appeared at a time when views about treatment in psychiatry tended to be polarised between psychotherapy and physical treatments, including drugs and electroconvulsive therapy - Sargant was the chief protagonist of the latter approach. Peter's own views about the treatment of anorexia nervosa evolved gradually along broader lines. Their second joint publication in the British Medical Journal suggested that insulin should be dropped from the treat-

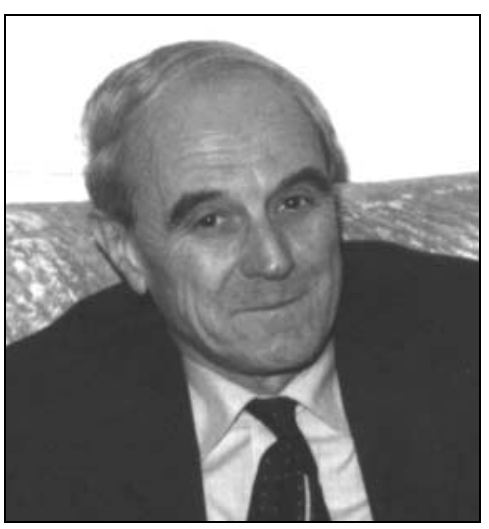

ment (Dally \& Sargant, 1966). Peter remained an expert in the use of psychotropic drugs but was soon heard to assert that 'every patient needs psychotherapy'.

Peter's views on chlorpromazine and insulin in anorexia nervosa, as well as psychotherapeutic programmes, were well presented in his book on anorexia nervosa, co-authored with Joan Gomez and $A$. J. Isaacs, which encapsulates the state of knowledge of eating disorders, in 1979. By then he had dismissed insulin therapy as lacking a logical approach, and he warned clinicians that its use in emaciated patients was particularly dangerous because of the risk of hypoglycaemia. He reported that chlorpromazine had been given routinely to all his patients until the early 1970s but it was not helpful in out-patients. From 1972 less than one-third of the patients admitted to his unit were administered chlorpromazine, and then largely to reduce anxiety and restlessness when faced with large meals as part of the weight gain programme. He had developed a robust treatment within the setting of the psychiatric unit. He avoided a comparison of this programme with behaviour modification but it clearly included the gain of privileges as weight increased. He fully acknowledged the role played by the nursing staff in his unit, who were urged to use their powers of persuasion and unending patience. If the nursing team did not succeed in getting a patient to eat, he would often sit with the patient at meal times until she finished the food placed before her.

Peter's research was essentially based on astute clinical observations. He recognised that although anorexia nervosa is mainly an illness in young people, another form can develop in those over 50. This he called 'anorexia tardive'. One form closely resembled the commoner early-onset type of anorexia nervosa but another form differed, with the patient being inactive and spending much of the day in bed. These older patients were unusually difficult to treat and the anorexia tardive may be a true suicidal gesture. Although they were often very depressed, antidepressant treatment was remarkably unhelpful. Peter advised sticking to the usual nursing techniques of persuasion and cajolery, and mobilising what remained of the family to cooperate with a refeeding programme.

As a psychiatrist, Peter was a man whose powerful presence was immediately felt as he entered the room. He captured the attention of patients, students and colleagues. His patients adored him. He was attractive to women in spite of, or because of, his lameness, a sequel of an attack of poliomyelitis in 1955. Much of his appeal came from his capacity to listen and his natural kindness towards anyone who needed his support. While teaching medical students at the Westminster Hospital, he succeeded in recruiting students into psychiatry.

To understand Peter's personality one should recount some of his life experiences both before and since becoming a psychiatrist. He was born in London on 2 January 1923, a son of a naval captain and dental surgeon. Anne Norwich, his longterm companion in later years, wrote that he was the second son of parents who 
had suffered a grievous loss when their first son died of scarlet fever in infancy (The Independent, 12 July 2005). From an early age Peter felt he could not rival this angelic, absent brother in his parents expectations. Peter also acquired a virulent form of ringworm which led him to a 1-year period of quarantine at the age of 5 and had profound long-term effects. He thought that his separation from other children later made him reserved. However, it turned him into an avid reader, and he read volumes that had lain unread in the house for many years, including Shakespeare, Gibbon and Macaulay.

After leaving the Ipswich School, he decided to follow the family's naval tradition and attended Dartmouth Royal Naval College, from which he emerged a midshipman at the beginning of the Second World War. He spent the War at sea; first in the Mediterranean where his ship was torpedoed and then towed across the Atlantic for repairs. He spent the later part of the War on HMS Swiftsure in the Pacific and Hong Kong and was promoted to full lieutenant. Soon after the atomic bomb attack on Nagasaki, he visited the area. He never forgot the black shadows of former buildings created by the radiation. In 1957 he was discharged on medical grounds: duodenal ulcers from which he continued to suffer for many years

On leaving the Navy he obtained a place to study medicine at St Thomas' Hospital, London, where he won several prizes, including those for surgery and psychiatry. He graduated in 1953. After his house jobs he began his training in psychiatry at St Ebba's Hospital, Epsom. At medical school he met and later married a fellow student, Ann, daughter of the law reformer, Claud Mullins.

Dr Ann Dally, his ex-wife, contributed to his obituary in The Times on the 28 July 2005. She described how it was at St Ebba's that he contracted poliomyelitis and was severely paralysed. He was extremely ill. She said it was typical of him that when his doctors wanted to put him in an iron lung he refused and managed to survive without it. He underwent intensive physiotherapy but was left with marked weakness of the right leg which led to permanent lameness. There are other anecdotes about this illness. Doctors in the hospital were offered the new Salk polio vaccine. He declined this prophylaxis, along with several colleagues. At a later stage, when disabled by his weak leg, he was given an electric wheelchair for use in the street. One day, however, he was overtaken by a steamroller and was so furious that he decided to obtain a car adapted so that he could drive again.

In 1961 he was appointed consultant at Westminster Hospital. He had already come under the influence of William Sargant who invited him to look after his private patients when he was away. $\mathrm{He}$ soon became well known to general practitioners and patients. His practice grew rapidly and he enrolled his wife Ann to help him. Although their marriage was dissolved in 1969, the separation was amicable and their mutual practice continued until they retired in 1994. Family tragedy struck when two of his sons died, Simon in 1989 and John in 1994. It is customary for the obituarist to draw a veil over personal grief but Peter himself lifted this veil in the case of Simon, who suffered from manic depressive illness and took his own life on Easter Sunday in harrowing circumstances. Two sons and two daughters survive him and he maintained a close interest in these children and his grandchildren.

Another difficulty, but of a professional nature, overtook Peter in the years after his retirement. The Peter Dally Clinic had been established in Hopkinson House, where the new facilities were available for patients with eating disorders. Two years later it was closed because of staff irregularities and management problems. When it was eventually reopened, Peter Dally's name was sacrificed with the aim of retrieving the reputation of the clinic, although the problems had arisen only after his retirement. Dr Peter Carter, Chief Executive of the new mental health trust wrote in The Times (12 August 2005), following the obituary in that paper (28 July 2005), that he had personally telephoned Dr Dally to explain fully the circumstances. He found Peter to be totally dignified and understanding, not only about the need to close the clinic but also to rename it when it reopened. He accepted that Peter would have been disappointed that his name was not going to live on as a tangible endorsement of his outstanding contributions to the subject of eating disorders. Peter readily supported the proposed action. Dr Carter concluded that, in the fullness of time, it might be possible to reinstate his name.

It would be a mistake to suggest that Peter did not succeed in overcoming the family tragedies and his physical incapacity: for example, far from being ashamed of his lameness he would hang his walking stick on the door of his office to indicate to visitors that he was within. He had a keen albeit mischievous sense of humour. He was particularly kind to secretaries and junior doctors. Patients and staff hung on his every word

DALLY, P. J. \& SARGANT,W. (1960) A new treatment of anorexia nervosa. British Medical Journal, ii, 1770.

DALLY, P. J. \& SARGANT,W. (1966) Treatment and outcome of anorexia nervosa. British Medical Journal, iii, 793 .

DALLY, P. J. \& GOMEZ, J. \& ISAACS, A. J. (1979) Anorexia Nervosa, pp. 113-118. London: Heinemann.

Gerald Russell
Naresh Gandhi

Formerly Consultant Psychiatrist in Intensive Care at the Park Royal Centre for Mental Health, Park Royal, North West London

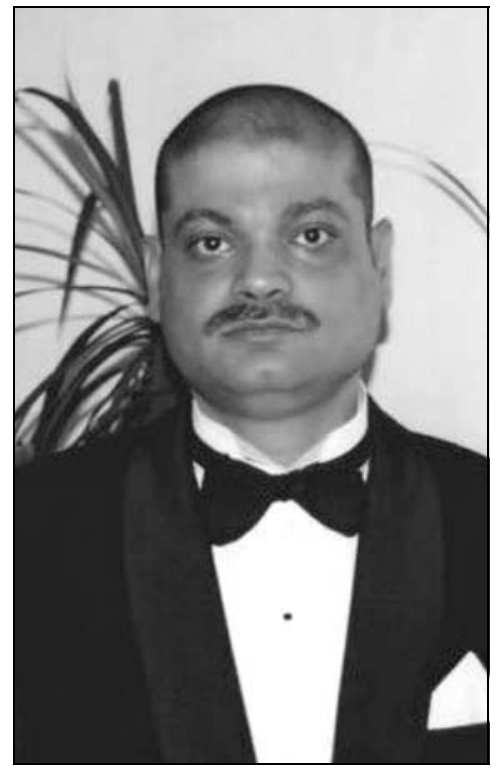

Dr Naresh Gandhi died from a bleeding duodenal ulcer on 14 August 2005. He was just 43.

Dr Gandhi graduated in Bombay in 1984 and obtained his MD in 1989. He was an outstanding student and, in addition to showing excellence in all areas of the medical curriculum, his flamboyance and cheery self-confidence made him a magnet for other students. He found time to edit an in-house university magazine and a science journal, which he continued to do with great success for many years. He decided to specialise in psychiatry early and came to England in 1989. After completing his senior house officer training and engaging in research projects, he was appointed as Lecturer in Psychiatry at Imperial College in 1993 before becoming a consultant in Intensive Care Psychiatry at the Park Royal Centre for Mental Health in 1995.

At Park Royal, he quickly established a comprehensive service for forensic patients in an area of the country which has been shown to have an excessive demand (Coid et al, 2001). His combination of great self-confidence, ability to rapidly analyse a situation and to make bold decisions made him a very popular and effective clinician. His court reports were a model of clarity and precision and his opinion was increasingly sought by solicitors who wanted someone to pronounce without obfuscation and 